\title{
MALNUTRITION AND LATENT SCURVY
}

\author{
BY \\ THEODOR FRöLICH, M.D., \\ Oslo.
}

\begin{abstract}
All investigators who have pursued the study of infantile scurvy, whether clinically or experimentally, have based their work upon Sir Thomas Barlow's classical description of the disease, and the light thrown by him upon its causes. The thoughts and ideas put forward by him in 1883 have received their final confirmation through modern scientific investigation.

Simultaneously with this, our knowledge of the clinical manifestations of the complaint has been extended, so that we can now also recognize cases of infantile scurvy that do not exhibit the typical symptoms characterizing the cases forming the basis of Barlow's description, which can never be forgotten by anyone who has had an opportunity of studying his fine collection of pathological-anatomical preparations.
\end{abstract}

The now well-known slighter cases of infantile scurvy show themselves by a more or less pronounced dystrophy, accompanied by anorexia, anaemia, occasionally by slight oedema, cessation of gain in or loss of weight, reduced power of resistance against infection, intestinal disturbances, but now and then also with more pronounced scorbutic symptoms, particularly haematuria (erythrocyturia minima), which in pronounced cases of scurvy in infants is one of the earliest, and in the opinion of many, the most common symptom of scurvy. On the basis of the symptoms here specified, it is possible in most instances, with a certain degree of probability, to recognize the majority of cases of pre-scorbutic dystrophy, but a definite diagnosis is only obtained ex juvantibus, when the child is given vitamin $\mathrm{C}$, which has specific and rapid effects in such cases.

The usual assumption has hitherto been that infantile scurvy makes its first appearance in the latter half of the first year, and this has been justified so far as it concerns the typical clinical cases, but there is no doubt that slighter, pre-scorbutic dystrophy may occur earlier if the child's mother has been nourished on food deficient in vitamin $\mathrm{C}$, or if the child's diet from the beginning has been deficient in vitamin C. In particular the latter factor 
may be of importance if on account of gastro-intestinal troubles the child has not been able to assimilate the vitamins administered, or if the child's need of vitamins is increased on account of acute or chronic infections.

Far less known, at any rate in northern countries, is the occurrence of slight, latent forms of beri-beri in small children, and this is no doubt mainly due to the difficulty in making a diagnosis, because here a specific symptom, like that of haematuria in scurvy, is lacking. It is a question, however, whether scorbutic dystrophy when accompanied by well-marked oedema, without any affection of the heart or kidneys, should be regarded as also dependent upon a lack of vitamin B. In this connection it should be remembered that A. Holst and Frölich ${ }^{1}$ found that in pigs a diet deficient in both vitamins $\mathbf{B}$ and $\mathbf{C}$ could produce a clinical picture characterized by haemorrhages, oedema and typical degenerative nerve changes; the clinical picture was regarded as that of a mixed form of scurvy and beri-beri. It was precisely this experimentally-produced mixed form that led me to regard the following case as an example of dystrophy, conditional upon a lack of both vitamins $\mathbf{B}$ and $\mathbf{C}$ in the diet.

\section{Case record.}

The patient was a girl, three months old, born at full term on July 17, 1934. She was of ordinary size and weight (not weighed at birth), and was breast fed for the first two months, subsequently being given daily only 500 c.c. of a mixture consisting of equal parts of milk, oat-meal gruel plus $20 \mathrm{gm}$. of sugar. For the last fourteen days before admission she received cod-liver oil, one teaspoonful, three times daily.

With this diet the child vomited after nearly every meal, and passed two to three times daily, thin, viscous, greenish stools. Simultaneously she had severe dermatitis (erythrodermia desquamativa, Leiner).

After one week on this diet, the child became swollen in the face, and later on there appeared swellings in her legs and back. She became markedly pale and listless.

On admission to hospital (October 16, 1934) the child was extremely debilitated, screamed with a weak, whimpering voice, presenting a poor turgor and tone. Her weight was 4,450 gm., length, $55 \mathrm{~cm}$., temperature, $36.5^{\circ} \mathrm{C}$. Her red corpuscles numbered 4,010,000 per c.mm., the white corpuscles, 14,200 per c.mm. Haemoglobin was 70 per cent. (Sahli). Röntgen examination showed a normal skeleton. The liver was slightly enlarged, the spleen was not enlarged. She presented the picture of an erythrodermia desquamativa. The skin of her face was swollen with a cutaneous oedema. The lower extremities were greatly swollen with an extensive cutaneous oedema showing pitting on pressure. The skin was tight and shiny.

The urine contained no albumin, sugar or pus; on the other hand, microscopic examination revealed a few red corpuscles, and some days later the urine also gave a positive reaction with the benzidin test. October 26, the oedema and haematuria had disappeared. On November 3 the urine was normal, and also on November 10. 
On the last date the patient was discharged in a good general condition, increasing in weight (to $4,780 \mathrm{gm}$.), and in length, $57 \mathrm{~cm}$. (increase $2 \mathrm{~cm}$.). The skin was normal, oedema had disappeared, the stools were normal, and the urine normal.

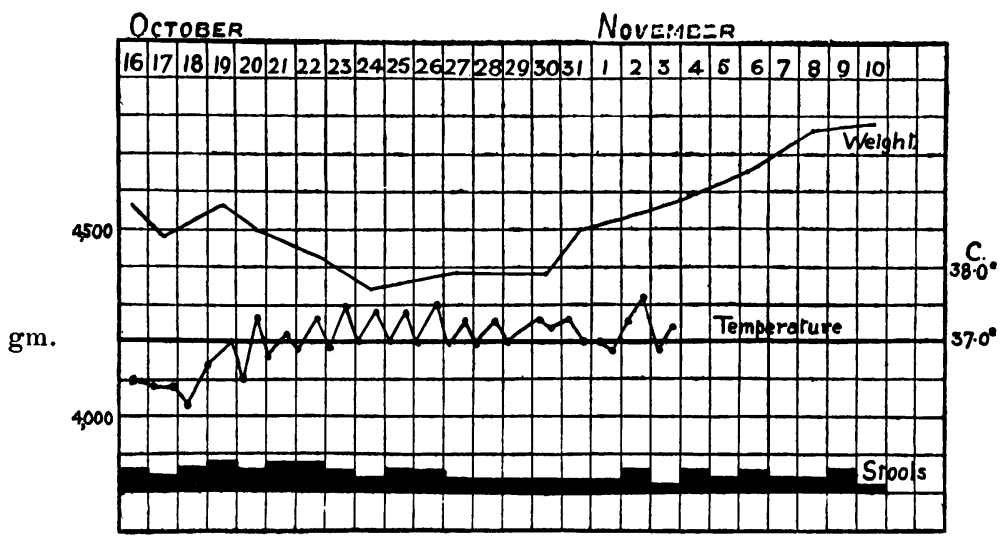

Discussion.

The diet upon which the patient became ill was calorically inadequate and insufficient with regard to albumin, amino-acids and mineral substances. In addition, it was very deficient in vitamins $\mathbf{B}$ and $\mathbf{C}$, whilst during the last fourteen days it contained sufficient vitamins $\mathbf{A}$ and $\mathbf{D}$.

It therefore appeared reasonable to explain the entire clinical picture, the acute gastro-enteritis, the dermatitis, haematuria and oedema, as a result of the entirely insufficient diet, a view that received strong support by the rapid improvement that took place after the employment of the following diet:-

The child was given $600 \mathrm{gm}$. of milk mixture ( 2 parts milk, 1 part water), to which were added $24 \mathrm{gm}$. of sugar, $15 \mathrm{gm}$. of cod-liver oil, $15 \mathrm{gm}$. of malt extract and $15 \mathrm{gm}$. of orange juice. Thereby the caloric requirements were covered by $120 \mathrm{cal}$. per $\mathrm{kgm}$. of bodily weight and the requirements of vitamins satisfied for all the necessary vitamins concerned.

On this diet the severe gastro-enteritis immediately improved, the oedema disappeared in the course of ten days, with a loss in weight of $230 \mathrm{gm}$., after which the patient increased in weight by $460 \mathrm{gm}$. in sixteen days. The haematuria also disappeared in the course of ten days, the dermatitis was quickly cured and the general condition was very good. 
This rapid alteration in the clinical picture gives strong support to the view that the patient's illness should be regarded as a deficiency disease resulting from an insufficient supply of vitamins $\mathbf{C}$ and $\mathbf{B}$.

\section{REFERENGE.}

1. Holst, A., \& Frölich, T., Ztschr. f. Hyg. u. Infectionskr., Berlin, 1912, LXXI, 1. 